\title{
Energy Justification of the Number of Tractors for Agricultural Operations
}

\author{
Camill A. Khafizov, Ramil N. Khafizov, Azat A. Nurmiev* and Ilgiz G. Galiev
}

Kazan State Agrarian University, Kazan, Russia

\begin{abstract}
The relevance of the problem under study is due to the need to substantiate the sufficient number of tractors used for various technological operations, depending on the volume of works performed, and taking into account their influence on the crop yield. The purpose is to develop the mathematical model of machine and tractor units used in technological operations by formalizing the vague concept of optimal agrotechnical timing of technological operations and calculating the optimal number of tractors to perform works by the total energy costs. The main research method is mathematical modeling of operations performed by machine-tractor units based on the system analysis and computational experiments and using the energy mathematical model. The article describes a criterion for optimizing the tractor parameters, dependences of the energy mathematical model of the unit. The results of computational experiments showed that for each operation there is an optimal number of tractors and tractor units minimizing the minimum total energy costs. Calculations were carried out when treating 1000 hectares with various tractors. It was revealed that the total energy consumption differs by 2 or more times. The required number of tractors depends on their main parameters, propeller parameters and other factors. It was revealed that with an increase in the volume of works, the required optimal number of tractors increases. The method for substantiating the required optimal number of tractors in technological operations will improve operations of tractors used by large agricultural producers, reduce the total energy costs for cultivating up to 12-16 thousand $\mathrm{MJ} / \mathrm{ha}$.
\end{abstract}

\section{Introduction}

Today much attention is paid to reducing crop losses [1-11].

At the same time, losses of products during the harvesting, post-harvesting and storage of products are of priority. However, it is known that one of the factors that determine the efficiency of crop production is the duration of other technological operations related to the soil preparation for sowing [12-14].

The lack of equipment and its ineffective use increase the duration of works and cause grain crop yield losses (up to $25 \%$ ) and potatoe yield losses (up to $45 \%)$, etc. [15-16].

The article continues the research on optimization of technical parameters, whose results are presented in [1720]. It discusses the methodology for substantiating the required amount of equipment to various technological operations in order to reduce the total direct and indirect energy costs, including the energy of the lost crop. This problem would be a simple production problem if it were possible to solve it using the available tools (methods). However, the methods used do not take into account the influence of the equipment on the crop yield (for example, the normative method of manning the equipment).

\section{Materials and Methods}

Justification of the number of tractors required to perform operations on 1000 hectares will be based on the systematic mathematical model of machine-tractor units based on the optimization of the total energy costs. The model has been verified and reflects the operation of real units [18-20].

To understand the influence of equipment parameters on yield losses, we will reiterate the optimization criterion and dependences of the energy mathematical model [17].

The energy criterion for identifying the required number of tractors taking into account the influence of the tractor parameters on the crop yield is as follows [17]

$E=E_{m . t r}+E_{m . i m p}+E_{r t s}+E_{u . c .}+E_{d r v}+E_{f o}+E_{a g r}+E_{\text {exp }} \rightarrow \min$, (1) where $E$ - specific total energy expenditure, $\mathrm{MJ} \cdot \mathrm{ha}^{-1}$;

$E_{m . t r}, E_{m . i m p}$ - energy spent, respectively, for the manufacture of a tractor and agricultural machine, per 1 hectare, $\mathrm{MJ} \cdot \mathrm{ha}^{-1}$;

$E_{r t s}$ - energy spent on all types of repair and technical service of a tractor and agricultural implement, $\mathrm{MJ} \cdot \mathrm{ha}^{-1}$;

$E_{\text {u.c. }}$ - energy spent on assembling and disassembling the seeding unit, $\mathrm{MJ} \cdot \mathrm{ha}^{-1}$;

\footnotetext{
Corresponding author: azat-nurmiev@mail.ru
} 
$E_{d r v}$ - energy spent by the machine operator on the control of the unit (turning, stopping and starting and shifting gears), MJ $\cdot$ ha $^{-1}$;

$E_{f o}$ - energy spent for fuel, MJ $\cdot \mathrm{ha}^{-1}$;

$E_{a g r}$ - energy of the crop lost due to a violation of the technological terms of the technological operation, $\mathrm{MJ} \cdot \mathrm{ha}^{-1}$;

$E_{\text {exp }}$ - energy of the crop lost due to soil compaction by the tractor wheels, MJ $\cdot \mathrm{ha}^{-1}$.

The procedure for calculating the components of the total energy costs of $E_{\mathrm{m} . t \mathrm{r}}, E_{\mathrm{m} . \mathrm{mpp}}, E_{\mathrm{rts}}, E_{\mathrm{u} . c .}, E_{\mathrm{drv}}, E_{\mathrm{fo}}, E_{\exp }$ is described in [17].

The wrong choice of parameters of the tractor, errors in the justification of the required number of units performing a given amount of works $S_{0}$ cause crop losses. Crop losses are caused by a violation of the optimal agrotechnical terms of works. The concept of the optimal agrotechnical period of works is introduced due to the need to perform technological operations in a short time, but it is difficult to justify quantitatively.

We propose to calculate the energy of grain lost due to the exceeded agrotechnical terms for performing technological operations, using the following dependencies (2)-(4) [17]:

$$
E a=\frac{\sum_{i=1}^{N_{-}-1}\left(C_{i} \cdot i \cdot W \cdot T_{s h} \cdot n_{s h}\right)+\left(N_{1}+1\right) \cdot \Delta i \cdot C_{l} \cdot W \cdot T_{s h} \cdot n_{s h}}{S_{0}},
$$

where $C_{L}$ - yield loss coefficient, $\mathrm{MJ} \cdot$ ha per day ${ }^{-1}$

$$
C_{\mathrm{L}}=Y \Delta y Q / 100 \text {; }
$$

where $Y$ - planned yield, $\mathrm{kg} \cdot \mathrm{ha}^{-1}$;

$\Delta y-$ loss of crop in \% for 1 day of violation of the optimal operation timings;

$Q$ - energy intensity of $1 \mathrm{~kg}$ of product (grain), $\mathrm{MJ} \cdot \mathrm{kg}^{-1}$;

$N_{i}$ - number of whole days in $\mathrm{N}_{1}$ (4);

$\Delta i$ - residual incomplete day in $\mathrm{N}_{1}$;

$S_{\mathrm{o}}$ - volume of work per season, per one seeding unit, for this operation, ha;

$$
N^{1}=\frac{S_{0}}{W \cdot T_{s h} \cdot n_{s h}},
$$

where $N_{1}$ - number of days required to perform the operation on the area $S_{0}$;

$n_{s h}-$ coefficient of shifts;

$T_{s h}-$ duration of shift, hours [17].

The calculation algorithm involves the calculation of the minimum number of tractors $-\mathrm{n}_{\min }$ for treating 1000 hectares of arable land, depending on factors $i$, under the condition of obtaining the minimum total energy costs $-\mathrm{E}$

$$
n_{\min }=\mathrm{f}(i) \text { at } E \rightarrow \min \text {. }
$$

\section{Results}

One of the options for substantiating the composition of the machine and tractor fleet and identifying the required number of tractors and agricultural machines is a largescale standard method designed for 1000 hectares of arable lands.

Conduct computational experiments and determine the number of tractors (by brands) required to treat 1000 hectares of arable lands in various technological operations and groups of technological operations combined by their energy intensity.

\section{Initial data for calculation:}

- Field area $=100$ hectares;

- Rutting length = $1 \mathrm{~km}$;

- Moving distance $=3 \mathrm{~km}$;

- Seed density $=800 \mathrm{~kg} / \mathrm{m}^{3}$;

- Load-bearing surface strength factor $=0.9$

- Volume of works = 1000 hectares;

- Duration of works per day = 8 hours;

- Planned yield = $40 \mathrm{c} / \mathrm{ha}$;

- Tire pressure $=0.16 \mathrm{MPa}$;

- Number of tractors = 10 units;

- Number of wheels on one side of the tractor $=1$;

- Coefficient of wheel adhesion to the soil $=0.5$;

- Coefficient of wheel rolling resistance $=0.17$;

- Tool resistivity $=2.8 \mathrm{kN} / \mathrm{m}$.

The results of computational experiments for the first group of technological operations with the specific resistance of an agricultural machine within 1-3 kN/m (harrowing, cultivation before sowing, sowing, etc.) are shown in Figure 1. The difference in total energy costs by brands of tractors is $15,000 \mathrm{MJ} / \mathrm{ha}$ (the difference in the energy consumption of tractors DT-75M and Buller485).

The lowest energy costs were observed when using tracked tractors DT-75M, T-150 (5000 MJ/ha). Wheeled tractors have a greater compacting effect on the soil due to their propellers, but crop losses and total energy costs vary significantly. Lower energy costs were observed for wheeled tractors of a smaller traction class. By the total energy consumption, the tractors were arranged in the following order: MTZ-82, MTZ-1221, K-3160, MTZ1520, T-215KAMAZ, etc.

The heaviest wheeled tractors JohnDeer-9430, Bueller-485 have the highest energy consumption (up to $17,500 \mathrm{MJ} / \mathrm{ha}$ ) even if the optimal amount is chosen for treating 1000 ha.

The number of tractors with the minimum total energy consumption depends on the traction class. When using tractors of low traction classes, their required number increases. Suppose the optimal number of MTZ82 tractors is 6, DT-75M is 4, and K-744R2 is 3 (Fig. 1).

In addition, the required number of tractors depends on the length of the working day, the shift ratio, the amount of works performed per season by one tractor, etc.

As you know, the large-standard method of manning the tractor fleet assumes a linear, directly proportional increase in the number of tractors, depending on the volume of works. Our calculations show that the relationship between the volume of works and the number of tractors is not linearly directly proportional. Let us assume that a twofold increase in the volume of works in the first group of technological operations did not cause a twofold increase in the required number of tractors. The need for DT-75M increased from 4 to 5 , for K-3160 - from 4 to 6, for DD-9430 - from 3 to 4, etc. (Fig. 1 and 2). 


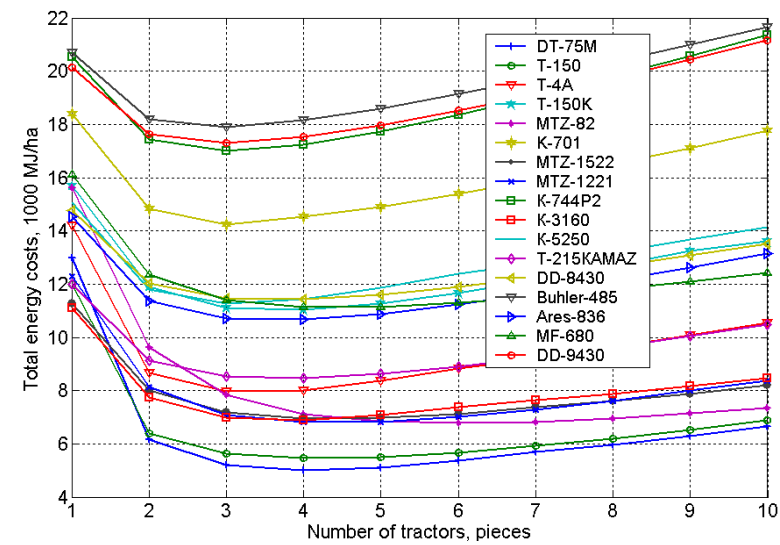

Fig. 1. The optimal number of tractors by brands in low energy intensity operations intensity $(0.8-3.2 \mathrm{kN} / \mathrm{m})$ for 1000 hectares

Figure 2 shows the graph of dependence of the total energy costs on the number of tractors used for the first group of technological operations with a seasonal load of 2000 hectares.

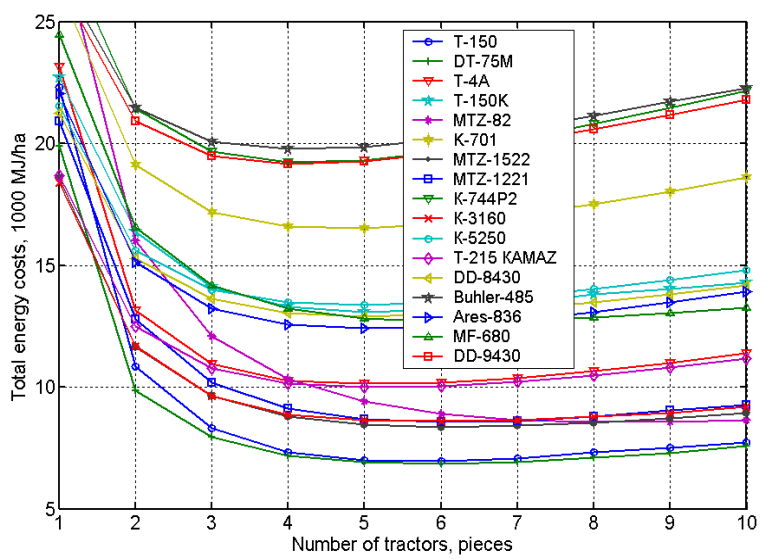

Fig. 2. The optimal number of tractors by brands in low energy intensity operations $(0.8-3.2 \mathrm{kN} / \mathrm{m})$ for 1000 hectares

Figure 3 shows the results of calculations of the optimal number of tractors for the second group of technological operations with the specific resistance of an agricultural machine within 3-7 kN/m (direct sowing with sowing units, soil disking, soil cultivation with combined agricultural machines, etc.).

Direct sowing often used in technologies with minimal tillage was chosen as a technological operation. Adjustments have been made to the initial data:

- Coefficient of wheel adhesion to the soil =0.6;

- Coefficient of wheel rolling resistance $=0.12$;

- Tool resistivity $=4.8 \mathrm{kN} / \mathrm{m}$;

The selected mathematical model for seeding units was developed taking into account features of the direct seeding.

For this group of technological operations, the minimum total energy costs are in the range of 4500-4800 MJ/ha. Of the wheeled tractors, the lowest energy consumption of 6700-6900 MJ/ha is observed in tractors with a mass of about 8 tons - T-215KAMAZ, MTZ-1522. The required number of tractors for treating 1000 hectares of arable lands is $4-5$ units. A larger number refers to tractors with less tractive efforts.

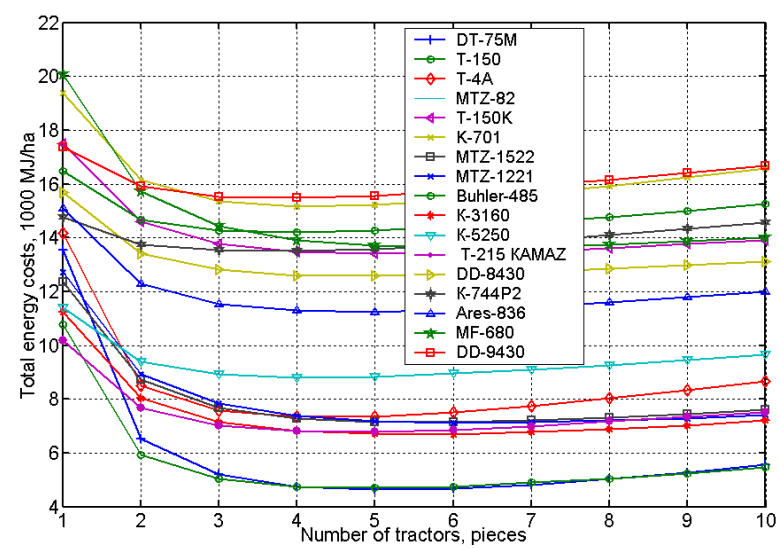

Fig. 3. Determination of the number of tractors for medium energy intensity operations for 1000 hectares

The results of similar calculations for the third, most energy-intensive group of technological operations (plowing, deep soil loosening, etc.) are shown in Figure 4.

The technological operation of plowing was chosen as an example for calculations. Initial data adjusted are as follows:

- Coefficient of wheel adhesion to the soil =0.7;

- Coefficient of wheel rolling resistance $=0.09$;

- Tool resistivity $=60 \mathrm{kN} / \mathrm{m}^{2}$;

- Plowing depth $=0.25 \mathrm{~m}$.

The mathematical model was selected for arable machines. It was developed taking into account peculiarities of the technological process.

The minimum total energy costs for this operation were observed in tractors Büller-485 and DD-9430 4200-4400 MJ/ha. The mass of these tractors is 16000-20000 tons. The optimal required number of tractors is 3. Caterpillar tractors are located in the upper part of the graph, and their total energy consumption is 9300-9500 MJ/ha.

High hourly productivity of the units is important to shorten the agro-term of the technological operation and to reduce crop losses. Crop losses due to the soil compaction by tractor propellers are compensated by a deep tillage of up to $30-40 \mathrm{~cm}$. Therefore, wheeled tractors of high traction classes are better.

The optimal number of most tractors is between 3 and 4.

As can be seen from the calculations, the largest number of tractors is required to perform second group operations in terms of energy intensity. These works are performed in early spring, with high soil moisture (soils are more compacted), and the percentage of crop losses is high. Spring works must be performed on a tight schedule in order to limit the loss of soil moisture, especially in areas with minimal accumulation.

Thus, the method for calculating the optimal number of tractors allows you to calculate the number of tractors that provide the minimum direct and indirect energy costs, including the energy of the lost crop. An increase in the number of tractors increases the costs of equipment repair and maintenance; a decrease in the mumber of tractors can increase the energy of the lost 
crop. Therefore, there is a minimum (optimum) in the dependence $\mathrm{n}_{\min }=\mathrm{f}(i)$.

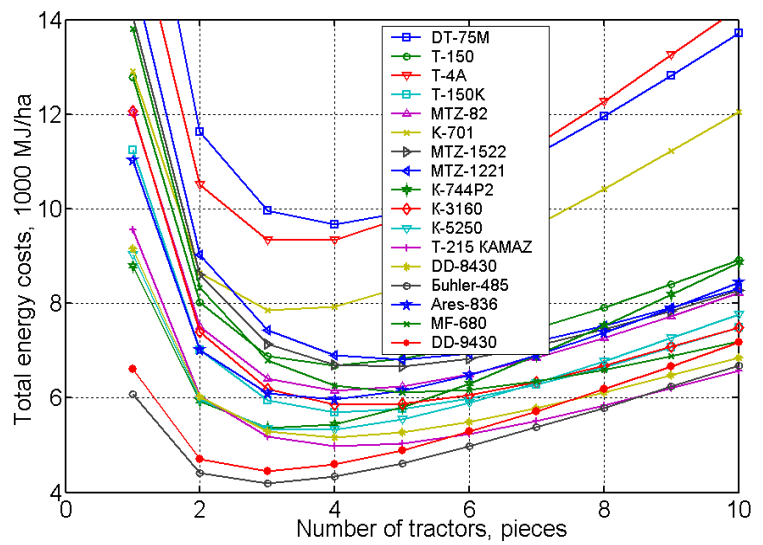

Fig. 3. Determination of the number of tractors for high energy intensity operations for 1000 hectares

Calculate the required amount of tractors used in several technological operations; this situation is a common occurrence in production conditions. The calculation results are shown in Figures 5-7.

Figure 5 shows the number of tractors for sowing with a SZ-3.6 seeder and plowing with non-reversible mounted plows PLN.

\section{Calculation}

\section{Initial data:}

- Field area $=100$ hectares;

- Rutting length $=1 \mathrm{~km}$;

- Moving distance $=3 \mathrm{~km}$;

- Seed density = $800 \mathrm{~kg} / \mathrm{m} 3$;

- Load-bearing surface strength factor $=0.9$

- Volume of works = 1000 hectares;

- Number of working hours per day = 16 hours;

- Planned yield = $40 \mathrm{c} / \mathrm{ha}$;

- Tire pressure $=0.16 \mathrm{MPa}$;

- Number of tractors = 10 units;

- Number of wheels on one side of the tractor $=1$;

- Coefficient of wheel adhesion to the soil =0.5;

- Coefficient of wheel rolling resistance $=0.17$;

- Coefficient of adhesion of wheels to the soil =0.7;

- Coefficient of resistance to rolling $=0.09$;

- Seeder resistivity $=2.8 \mathrm{kN} / \mathrm{m}$;

- Plow resistivity $=60 \mathrm{kN} / \mathrm{m}^{2}$;

- Plowing depth $=0.25 \mathrm{~m}$.

Calculation results:

- Optimum seeder width $=14 \mathrm{~m}$;

- Optimum plow width $=3.5 \mathrm{~m}$;

- Optimum seeder speed $=13 \mathrm{~km} / \mathrm{h}$;

- Optimum plowing unit speed $=12 \mathrm{~km} / \mathrm{h}$;

- Optimum tractor weight $=11 \mathrm{t}$;

- Required power of the sowing tractor engine $=28 \mathrm{~kW}$;

- Required power of the plowing tractor engine $=306 \mathrm{~kW}$;

- Traction efficiency $=0.553$;

- Seeding slip coefficient $=13.77$;

- Plowing slip coefficient $=12$;

- Seeding unit productivity $=7.72 \mathrm{ha} / \mathrm{h}$;
- Plowing unit productivity $=2.58 \mathrm{ha} / \mathrm{h}$;

- The minimum amount of energy costs for two operations $=11488.6 \mathrm{MJ} / \mathrm{ha}$.

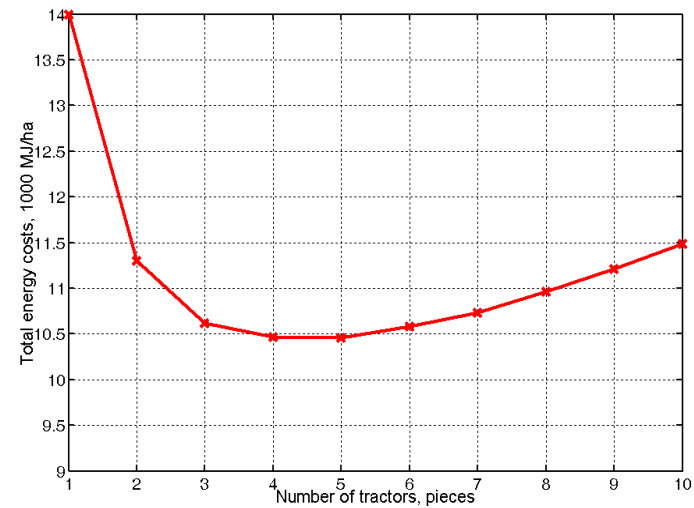

Fig. 5. Determination of the required number of tractors for sowing (SZ-3.6) + plowing (PLP) on an area of 1000 hectares

If the optimal tractor weight for sowing was 2.6-6.0 tons (4 tractors are needed per 1000 hectares), and for plowing it was 13-16 tons (3 tractors are required), a tractor with compromise parameters should have a mass of 10-15 tons, depending on the soil resistivity; the engine power should be $260-360 \mathrm{~kW}$. The number of tractors required for both operations is 4 or 5 , which can be seen in Figure 5. This will ensure the minimum amount of energy costs for two operations $-10,420 \mathrm{MJ} / \mathrm{ha}$.

Figure 6 shows the optimal number of tractors for a medium-energy-intensive technological operation of soil preparation for sowing with a KPIR unit and a highenergy technological operation of plowing. The optimal weight of the tractor is 10-11 tons (5-6 tractors per 1000 hectares), for plowing - 13-16 tons ( 3 tractors); the compromise tractor should have a weight of 12-16 tons, the engine power should be $280-400 \mathrm{~kW}$. The required number of tractors with compromise parameters is 4 . The total energy costs for two units in two technological operations is $21,700 \mathrm{MJ} / \mathrm{ha}$.

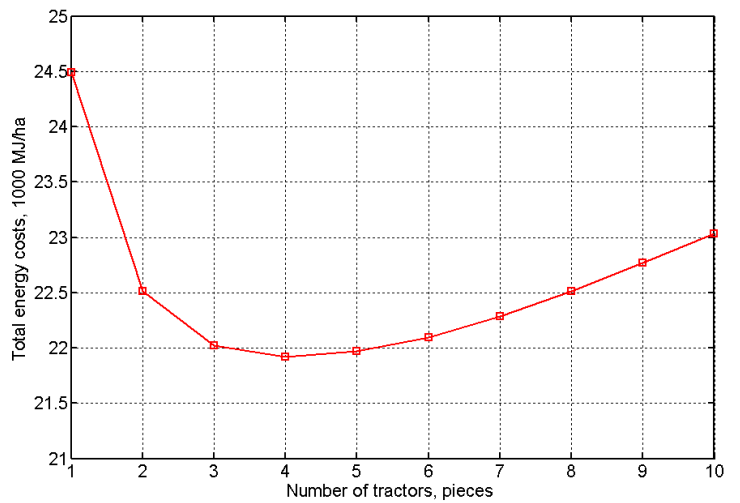

Fig. 6. Determination of the optimal number of tractors for preparing the soil for sowing with a combined unit and plowing on an area of 1000 hectares 


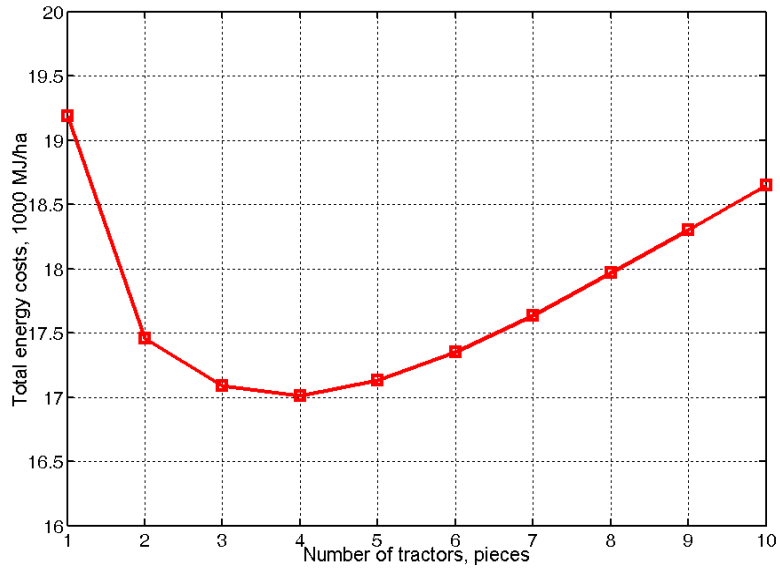

Fig. 7. Determination of the number of tractors for direct sowing (Agromaster) + deep loosening (GWP) per 1000 hectares of arable lands

Figure 7 shows the number of tractors for direct sowing with the no till technology and deep soil loosening. The optimal weight of the tractor is 12-19 tons, the engine power is $286-415 \mathrm{~kW}$, depending on the specific soil resistance. 4 tractors per 1000 hectares of arable lands are required.

\section{Conclusion}

1. The developed method for identifying the required number of tractors taking into account the influence of tractor parameters on the grain yield makes it possible to determine the optimal number of tractors.

2. Calculations for determining the need for tractors per 1000 hectares showed that

- for early spring works with low energy consumption, tractors with a weight of 4-8 tons with an engine power of 60-170 kW have an advantage. With an increase in the energy costs, tractors are ranked as follows: MTZ-82, MTZ-1221, K-3160, MTZ-1520, T-215KAMAZ, etc. The optimal number of tractors ranges from 3 to 4 - for most of the brands and up to 6 for MTZ-82;

- similar calculations for technological operations with a specific resistance from $\mathrm{k}=3 \mathrm{kN} / \mathrm{m}$ to $7 \mathrm{kN} / \mathrm{m}$ showed that the optimal number of tractors providing minimum total energy costs is 4 (T-215KAMAZ) or 5 (K-3160);

- calculations carried out for high-energy technological operations - plowing $\left(\mathrm{k}=60 \mathrm{kN} / \mathrm{m}^{2}\right)-$ showed that the minimum total energy costs are provided by tractors of a high traction class - John Deere-9430, Buller-485. The required number of these tractors is 3 . T-215 KAMAZ, K-5250, K-744R2 showed good plowing results. The total energy consumption for plowing was 5200-5500 MJ/ha. They rank third, fourth and fifth; their required number is 4 per 1000 ha.

3 . The wrong choice of a tractor brand can increase the total energy consumption by $12000 \mathrm{MJ} / \mathrm{ha}$. An increase or decrease in the number of tractors increases total energy costs. The difference can be up to 4000 $\mathrm{MJ} / \mathrm{ha}$.
4. The computational experiments revealed that the required number of tractors to treat a given amount of works increases in direct proportion to the increase in the volume of works. For example, if for sowing 1000 hectares of arable lands 4 MTZ-1221 tractors should be used, for sowing 2000 hectares of arable lands, 6 tractors are required.

5. The optimal tractor weight for performing lowenergy and high-energy-intensive operations, as well as medium-energy-intensive and high-energy-intensive operations is between the weights of tractors that are optimal for performing individual operations. The same situation is with engine power. The required number of tractors is 4 .

\section{References}

1. FAO, Food wastage footprint: Impacts on natural resources (2013).

2. R.J. Hodges, J.C. Buzby, B. Bennett, Postharvest losses and waste in developed and less developed countries: opportunities to improve resource use, J. of Agricult. Sci., 149, 37-45 (2011)

3. S. Sipho, Potential causes of postharvest losses, lowcost cooling technology for fresh produce farmers in Sub-Sahara Africa, African J. of Agricult. Res., 16(5), 553-566 (2020), DOI: 10.5897/AJAR2020.14714

4. A.D. Murashev, Methods of optimal design of agricultural production processes (MSKhA, Moscow, 2012), 267 p.

5. A.N. Skorokhodov, Optimization of the structure and composition of technological complexes for the implementation of production processes, Int. sci. J., 2, 82-92 (2012)

6. I. Maksimov, N. Adigamov, A. Mustafin, D. Khaliullin, I. Gayaziev, A. Matyashin, R. Lukmanov, Theoretical fundamentals for determining soil erosion potential, Periódico Tchê Química, 16(31), 540-557 (Porto Alegre, RS. Brasil, 2019)

7. E.M. Gross, B.P. Lahkar, N. Subedi, V.R. Nyirenda, L.L. Lichtenfeld, O. Jakoby, Does traditional and advanced guarding reduce crop losses due to wildlife? A comparative analysis from Africa and Asia, J. for Nature Conservat., 50, 125712 (2019), Retrieved

from: https://doi.org/10.1016/j.jnc.2019.125712

8. E.E. Oldfield, M.A. Bradford, S.A. Wood, Global meta-analysis of the relationship between soil, organic matter and crop yields, The Soil, 5, 15-32 (2019), DOI: 10.5194/soil-5-15-2019

9. C.J. Lowry, G.P. Robertson, D.C. Brainard, Striptillage decreases soil nitrogen availability and increases the potential for $\mathrm{N}$ losses in a cover cropped organic system, Agricult., Ecosyst. \& Envir., 319, 107524 (2021), Retrieved from: https://doi.org/10.1016/j.agee.2021.107524 
10. T. Colombi, Th. Keller, Developing strategies to recover crop productivity after soil compaction $-\mathrm{A}$ plant eco-physiological perspective, Soil and Tillage Res., 191, 156-161 (2019), Retrieved from: https://doi.org/10.1016/j.still.2019.04.008

11. A.D. Kleshchenko, V.M. Lebedeva, T.A. Goncharova et al., Assessment of yield losses from drought using a dynamic-statistical model for predicting the productivity of agricultural crops, Meteorol. and Hydrol., 4, 94-102 (2016)

12. V.A. Zubina, Basic agrotechnical requirements for optimizing the harvesting of agricultural crops, Coll. of mat. of the VIII Int. Distance Sci. and Pract. Conf. of Young Scientists (Krasnodar, 2018), pp. 69-76

13. A.V. Lavrov, V.G. Shevtsov, V.A. Zubina, Analysis of the influence of the duration of agricultural operations on crop losses in the soil and climatic conditions of the Kaluga region, Mat. of the Int. Sci. and Pract. Conf. of FGBNU VNIIMZ Adaptive landscape farming systems - the basis for the effective use of reclaimed land (Tver, 2017), pp. 35-39

14. A.I. Ryadnov, O.A. Fedorova, O.I. Poddubny, Loss of grain from the increase in the harvesting time of grain crops, Bull. of the Nizhnevolzhsky agricult. Univ. complex Sci. and higher profess. ed., 2(58),
375-384 (2020), DOI 10.32786 / 2071-9485-202002-37

15. V.M. Beilis, Duration of mechanized field agricultural work, Monograph (Res. Inst. of Agricult. Mechan., Moscow, 2005), 163 p.

16. D.T. Khaliullin, A. Belinsky, A. Valiev, R. Lukmanov, G. Bourges, Optimization of plow adjustment, BIO Web of Conf., 27, 00103 (2020)

17. K.A. Khafizov, Ways to reduce energy costs in production processes in agriculture (Kazan State Univ. Press, Kazan, 2007), 272 p.

18. C. Khafizov, R. Khafizov, A. Nurmiev, I. Galiev, Optimization of main parameters of tractor and unit for plowing soil, taking into account their influence on yield of grain crops, Engin. for Rural Devel., 19, 585-590 (2020)

19. C. Khafizov, R. Khafizov, A. Nurmiev, R. Usenkov, Optimization of main parameters of tractor and unit for deep processing of soil according to criterion total energy costs, Engin. for Rural Devel., 19, 603-608 (2020)

20. K.A. Khafizov, R.N. Khafizov, A.A. Nurmiev, I.G. Galiev, Justification of the optimal annual load on the tractor providing for its parameters stress on the formed crop, BIO Web of Conf., 17, 00022 (2020) 